\title{
Tobacco policy rating form: a tool for evaluating worksite and tribal smoking control policies
}

\author{
Russell E Glasgow, Shawn M Boles, Edward Lichtenstein, Lisa A Strycker
}

\begin{abstract}
Objective-To report on the development and validation of a rating scale to code the various components of written tobacco policies.

Design-A one-page Tobacco Policy Rating Form (TPRF) was developed to apply to written policies in both worksites and American Indian tribes. Fifteen worksite and 24 tribal tobacco policies from a diverse set of companies and tribes of varying size and economic status were rated on the TPRF by two separate sets of experienced and inexperienced raters. Kendall's coefficient of concordance $(W)$ was computed to measure inter-rater agreement.

Results-The scale was found to produce a high level of agreement when used by both experienced and inexperienced raters on both tribal and worksite policies. For experienced raters, $W=0.92, P<0.0001$ for tribal policies and $W=0.97, P<0.0001$ for worksite policies; for inexperienced raters, $W=0.89, \quad P<0.0001$ for tribal policies and $W=0.96, P<0.0001$ for worksite policies.

Conclusions-The TPRF seems worthy of future use as a tool to rate the strength and comprehensiveness of written tobacco policies. It may be extended to other settings such as schools and municipalities, or used by investigators studying behavioural or economic consequences of smoking policies. Those interested in policy change may find the TPRF useful as a way of describing existing policies and as a quantitative measure of change.
\end{abstract}

(Tobacco Control 1996;5:286-291)

Keywords: tobacco policy; rating scale; smoking control; behaviour change.

\section{Introduction}

There is increasing recognition of the importance of policy and environmental approaches to tobacco control and other risk-producing behaviours. ${ }^{1-8}$ As the limits of purely educational and/or skills-based approaches to health promotion become more widely accepted, ${ }^{19}$ more programmes are realising that the larger social environment in which one lives and works must also be addressed to produce lasting behaviour change. ${ }^{10}$

In the smoking control area, there is an increasing focus on restricting access to cigarettes, particularly among the young. ${ }^{11}$ As efforts to strengthen smoking control policies increase, the need for reliable, validated, and easy-to-use procedures to classify such policie $\vec{P}$ also increases. Rigotti and colleagues have developed procedures to classify communitw

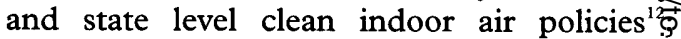
Forster $e t a l^{13}$ and Velicer $e t a f$ have develope $\Phi^{\text {T }}$ questionnaire measures of personal attitudesi toward tobacco control policies. However, t\$ our knowledge, no standard procedures exis? to classify and quantitatively describe an organisation's smoking policy.

Our research group developed the Tobacc Policy Rating Form (TPRF) based upon ou experience in worksite health promotion ${ }^{14-19}$ and from our experiences in working with northwest (United States) Indian triba councils $^{1718}$ to develop or enhance tobacce control policies, or both. From this perspective, we felt that there were five impor tant aspects of tobacco policies: providing 8 rationale for the policy; level of restrictions an policy stringency; presence of a specifie procedure for policy enforcement; components that reduce availability of cigarettes; and provie sion of resources to assist those motivated te. quit smoking. ${ }^{31920}$ The purposes of this papes are to: (a) describe the development and preliminary validation of the TPRF; (b) evalu ate how well this form works in both worksite and tribal policy contexts, when used by either experienced or inexperienced raters; and (cळ discuss how the TPRF can be used for botti assessment and intervention purposes, as welf as the strengths and limitations of the form

\section{Methods}

Data for this paper were collected as part of two larger programmes of research. The firstu was a collaborative arrangement to develop implement, and evaluate a consultative proces that supported Indian tribal councils' adoptio of more effective tobacco use policies. ${ }^{1718}$ The् second source for this study was ouf experience developing and evaluating worksite smoking policies as part of a worksite-based health improvement project, ${ }^{1{ }^{16}}$ which empha sised policy and other "environmental control' approaches to worksite health promotion. ${ }^{2122}$ ?

In the course of conducting these projects, $\infty$ one-page form was developed and piloted to rate the strength and comprehensiveness of̂. written tobacco policies. The goal was to create an instrument that would provide a reliable, standardised measure of written tobacco policies in either of these settings, while requir- 
ing minimal levels of rater training and expertise.

\section{INSTRUMENT DESCRIPTION}

As Figure 1 shows, the TPRF is a one-page instrument on which raters code the five above-mentioned dimensions of a given written tobacco policy: "Rationale for Policy", "Indoor Restrictions", "Enforcement", "Availability of Cigarettes", and "Cessation Resources." Incorporated into the form are instructions to assist raters in scoring policies consistently with minimal training. Each of the five dimensions contains one or more elements that may be included in a written tobacco policy. In the Rationale for Policy category, raters enter scores indicating whether the policy mentions anything about (a) the health consequences of tobacco or (b) the hazards associated with environmental tobacco smoke. In the Indoor Restrictions category, restrictions on smoking and chewing are rated separately. Any statements about (a) penalties or (b) an implementation/resolution process for policy non-compliance are scored in the Enforcement category. In the Availability of Cigarettes category, (a) cigarette vending machine limitations and (b) statements about the importance of limiting youth access are rated. Finally, statements about support or providing quitting assistance to smokers are rated in the Cessation Resources category. For most items, raters mark a score of one or greater to indicate that the element is contained in the policy, or a zero score to reflect that it is lacking. $f$ Total scores can range from 0 to 14 , with higher numbers reflecting increasingly comprehensive policies.

SAMPLE POLICIES AND INSTRUMENT RELIABILITY To test the reliability of this instrument for both experienced and inexperienced raters, we obtained 15 worksite and 24 tribal policies from worksites and tribes of diverse sizes, locations, and types. $\neq$ The policies represented a broad range of complexity and stringency, varying from one-page memoranda to three-page resolutions. The four authors, serving as experienced raters, rated the 15 worksite policies first, reviewed the ratings, refined the criteria, and then used them to rate a set of 24 tribal policies.

To train the inexperienced raters, we created two prototype policies, one tribal and one worksite, to illustrate policy variations found across content scoring areas. $\$$ Two pairs of

*The TPRF is available on request from the authors by mail or fax (+1 5414841108$)$, or electronically at <http://www.ori.org $\sim$ shawn/public/tprf/ $>$.

tSome items that were considered to be of special importance-for example, smoking restrictions, chew restrictions, and penalties-were weighted with scores greater than one.

than one. †The authors are grateful to Glorian Sorensen of the WellWorks
Project ${ }^{34}$ and Kerri Lopez of the Northwest Portland Area Indian Health Board for providing us with worksite and tribal policies. The tribal policies were solicited from northwes Indian tribes in our study working with tribal councils to develop or enhance tobacco control policies, or both. The worksite policies were collected as part of several worksite health improvement projects. We used all policies received from these samples, they provided a reasonably diverse range of policies from different regions and were seen as good examples of worksite and tribal tobacco policies. inexperienced raters (two secretarial support staff and two mid-level managers) were given a brief (15-minute) training osession that consisted of: (a) an overview of tige rating form; (b) practice in rating the tho prototype policies; and (c) review and discêssion of their sample policy ratings. Each of the four inexperienced raters then individuallo rated both worksite and tribal policy sets. The support staff coded the worksite policies first and the tribal policies second, while for the mid-level managers this order was reverse

क

ANALYSES

For an instrument such as the $\overrightarrow{\mathrm{e}}$ TPRF, two important issues are internal cousistency and inter-judge agreement. Interna consistency was addressed by computing erronbach's $\alpha$. Spearman rank order correlatian coefficients were generated to compare agroment among experienced and inexperience $\Phi$ rater pairs, whereas overall inter-judge agreement was addressed with Kendall's gefficient of concordance. ${ }^{23}$ The Kendall's stopistic provides a natural extension of Spearman's $\rho$ to measuring the association among more than two raters' scores on more than twe items. It is superior to both $\kappa$ for multiple rgers ${ }^{24}$ and per cent agreement when applied to ordinal ratings such as those contained in the TळRF.

Inter-item reliabilities were computed based on data from all eight raters on a policies. The coefficient of concordance (W) Cos computed for the set of experienced rate? the set of inexperienced raters, and all rates ${ }^{25} \mathrm{~W}$ ranges from 0 to 1 . The significance of $W$ was tested using the Friedman $\chi^{2}$ statistic. ${ }^{23}$

To examine the structure of thie data, visual displays were produced compafing the rater sets on total policy scores orfify. For these displays, individual experience $\$$ raters were paired with individual inexperiepeed raters in all possible combinations, anc a plot was produced of the experienced rafer set scores against the inexperienced rate 3 scores. This type of scatterplot display is gescribed by Cleveland ${ }^{26}$ as a useful method for illuminating patterns in bivariate data. $\emptyset$

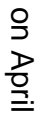

\section{Results}

Summary comprehensive scores from 0 to 12 on worksite policies, with aumedian of 5 . For tribal policies, summary \&oores ranged from 1 to 12 , with a median of $6_{\odot}^{\mathrm{C}}$

Internal consistency of the total policy score was found to be moderate (stand rolised Cronbach's $\alpha=0.76$ for all policies and all raters combined). Of the 10 items contrubuting to the total score, only two (limitson vending machines and effective enforcement date) led to higher internal consistency wen excluded from the scale. The lack of internigl consistency for these items stemmed primarify from (a) the absence of youth-related item in worksite

\section{ํ.}

These prototype policies are available on request by mail or fax, or electronically at <http://www.ori.org/ shawn/public/ tprf/>.

TThese labelled displays are available electronically at <http://www.ori.org/ shawn/public/tprf/>. 


\section{Written Tobacco Policy Rating Form}

Policy Code \#
Date
Rater 10 \#

\section{General Rules and Guidelines:}

1. Do not infer what you think a statement means. If a policy is silemt on an issue, score it "0".

2. When in doubt or if you can't decide, use the lower score (e.g., " 0 " instead of "1"; "I" instead of "2").

\section{A. Rationale for Pollicy}

\begin{tabular}{|c|c|c|}
\hline Whath iblonslor cencrel & $\begin{array}{l}p=n a \\
1 \neq y=s\end{array}$ & 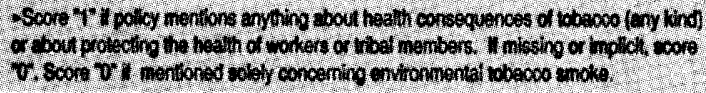 \\
\hline $\begin{array}{l}\text { - Environmental Tobacco smoke } \\
\text { Pigks fationale }\end{array}$ & $\begin{array}{l}0=\text { no } \\
1=\text { yos }\end{array}$ & $\begin{array}{l}\text {-Score "I" only if policy mentions ETS, or sinilar content such as secondhand smoke, } \\
\text { eflects of smoking on others, wc. }\end{array}$ \\
\hline
\end{tabular}

\section{B. Indoor Restrictions}

\begin{tabular}{|c|c|c|}
\hline moling Destritions & 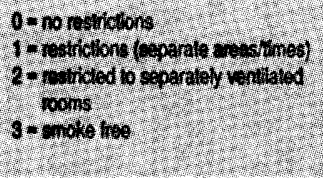 & 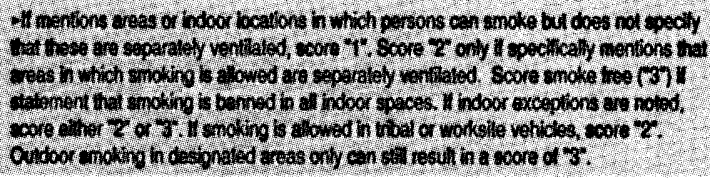 \\
\hline Chew Restrictions & $\begin{array}{l}0 \text { - no restrictions stated } \\
1 \text { - moderate restictions } \\
2 \text { - che ban }\end{array}$ & 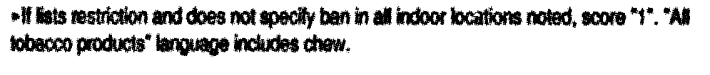 \\
\hline
\end{tabular}

\section{Enforcement}

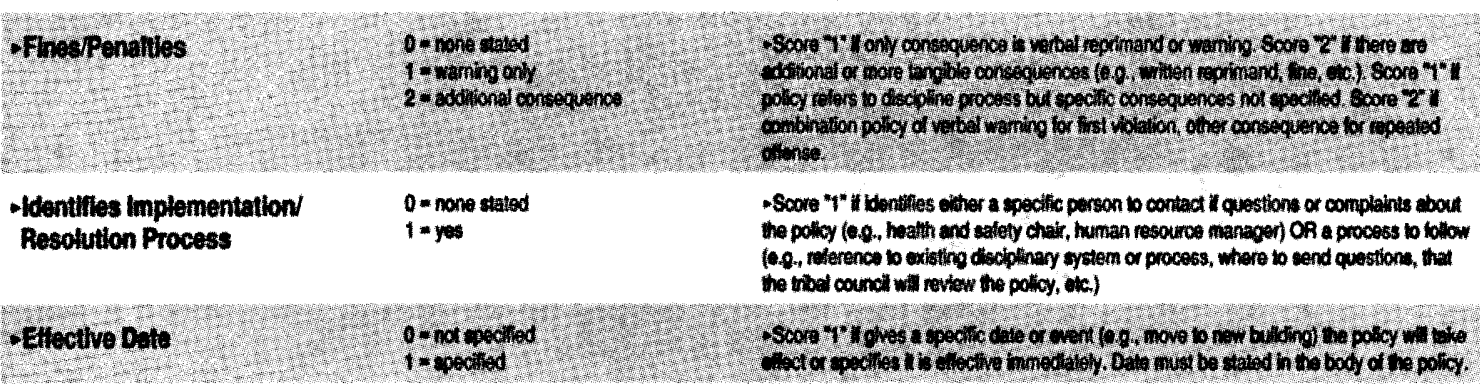

\section{Avallabillty of Cigarettes}

\begin{tabular}{|c|c|c|}
\hline Limils Vending Machmos & $\begin{array}{l}0=\text { no } \\
1=\text { yes }\end{array}$ & 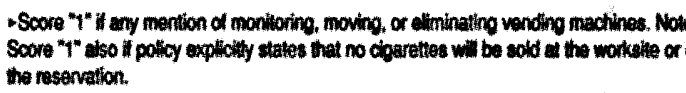 \\
\hline 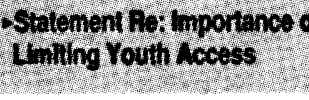 & $1+n$ & 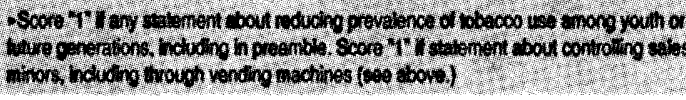 \\
\hline \multicolumn{3}{|c|}{ E. Cossation Resources } \\
\hline $\begin{array}{l}\text { - Spoctiles Nonemoking } \\
\text { Assistance for Snokers }\end{array}$ & $\begin{array}{l}0=n 0 \\
1-y e s\end{array}$ & 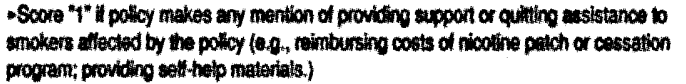 \\
\hline
\end{tabular}

-TOTAL SCONE

policies and (b) the difficulty of coding the effective date of implementation for tribal policies.

INTER-RATER AGREEMENT

Table 1 presents a summary of Kendall's coefficients for written tobacco policy ratings. These data revealed a high level of agreement among both experienced and inexperienced raters for summary comprehensiveness score assigned to both tribal and worksite written tobacco policies. Experienced raters generated coefficients ranging from 0.97 for worksite policies to 0.92 for tribal policies, while for inexperienced raters comparable values were 0.96 and 0.89 . Combining all raters into a single group yielded coefficients of 0.96 for worksite policies and 0.81 for tribal policies. 
Table 1 Coefficients of concordance for written tobacco policy ratings by policy setting and rater experience

\begin{tabular}{|c|c|c|c|c|c|c|c|}
\hline \multirow{2}{*}{$\begin{array}{l}\text { Stringency } \\
\text { scale }\end{array}$} & \multirow[b]{2}{*}{ Item } & \multicolumn{3}{|c|}{15 Worksite policies } & \multicolumn{3}{|c|}{24 Tribal ळ̈licies } \\
\hline & & Experienced & Inexperienced & All & Experienced & Inexperianced & All \\
\hline \multirow[t]{2}{*}{ A } & General health rationale & 10 & 0.904 & 0944 & 0.763 & ${ }_{0751} \overrightarrow{\overrightarrow{1}}$ & \\
\hline & ETS risks rationale & 0.936 & 0.791 & 0.851 & 1.0 & $0.828 \div$ & 0.847 \\
\hline \multirow[t]{2}{*}{ B } & Smoking restrictions & 0.897 & 0.956 & 0.921 & 0.797 & $0.669 \overline{\mathrm{G}}$ & 0.638 \\
\hline & Chew restrictions & 0.883 & 0.725 & 0.757 & 0.851 & 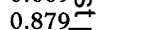 & 0.787 \\
\hline \multirow[t]{3}{*}{ C } & Fines/penalties & 0.880 & 0.989 & 0.931 & 0.941 & 0.949 을 & 0.928 \\
\hline & $\begin{array}{l}\text { Identifies implementation } \\
\text { process }\end{array}$ & 0.707 & 0.804 & 0.701 & 0.729 & $0.652 \frac{\bar{\sigma}}{\bar{c}}$ & 0.623 \\
\hline & Effective date & 0.796 & 0.912 & 0.820 & 0.587 & $0.709 \widetilde{\nabla}$ & 0.551 \\
\hline \multirow[t]{2}{*}{ D } & Limits vending machines & $1 \dagger$ & & $1 \dagger$ & 0.646 & 0.8280 & 0.734 \\
\hline & Youth access statement & $1+$ & $0.25^{\star}$ & $0.125^{\star}$ & 0.893 & $0.830 \stackrel{\omega}{\omega}$ & 0.830 \\
\hline $\mathrm{E}$ & Cessation resources & 1.0 & 1.0 & 1.0 & 0.889 & $0.797 \rightarrow$ & 0.667 \\
\hline \multicolumn{2}{|l|}{ Total } & 0.971 & 0.961 & 0.958 & 0.915 & $0.894 \stackrel{0}{-}$ & 0.814 \\
\hline \multicolumn{8}{|c|}{$\begin{array}{l}\text { All coefficients of concordance are significant }(\mathrm{P}<0.001) \text { except for those designated with an asterisk. } \\
\text { ETS = environmental tobacco smoke. } \\
\text { t These are items for which coefficients could not be computed since there was no variability across judges' scois. For each of } \\
\text { these items, there was } 100 \% \text { agreement as to the absence of the item from the policy. }\end{array}$} \\
\hline
\end{tabular}

Sizeable associations $(P<0.001)$ were found in the set of experienced raters, in the set of inexperienced raters, and among all raters on scores for each of the policy elements contributing to total scores. The sole exception was the youth access statement in the worksite policy set. Lack of agreement on this item is seen to indicate that youth access is not an appropriate measure of a tobacco policy for worksites (where young people are not ordinarily present). Excluding this item, coefficients of concordance on individual items ranged from 0.55 to 1.0 , with a median of 0.82 .

The "Indoor Restrictions" dimension, or stringency scale $\mathbf{B}$, is arguably the most important component of the overall score and, as can be seen in figure 1 , is weighted the most heavily. On this scale, experienced raters produced satisfactory ratings for both chewing and smoking components, in both worksite ( $W=0.88-0.90)$ and tribal settings $(W=0.80-0.85)$. There was greater variability among inexperienced raters, however ( $W=0.67-0.96)$, and in general these coefficients were somewhat lower than for experienced raters-especially for smoking restrictions in tribal settings.

For experienced raters scoring worksite policies, there was perfect agreement for general health rationale and cessation resources items and least agreement on identification of the implementation process and effective date items (table 1). For tribal policies, experienced raters agreed perfectly on the environmental tobacco smoke item and agreed least on items related to effective date and vending machine limits.

For inexperienced raters scoring worksite policies, perfect agreement was reached on the cessation resources item and near-perfect agreement on the fines/penalties item, whereas agreement was lowest on items regarding environmental tobacco smoke risks rationale, chew restrictions, and youth access. For tribal policies, inexperienced raters agreed most on the fines/penalties item and least on smoking restrictions and implementation process.

On both policy sets, Spearman correlations comparing total scores on pairs of individual raters within each rater set were generally high.
For summary policy compgehensiveness scores, $\rho$ ranged from 0.77 to 0.99 for pairs of raters in the experienced and $\vec{f}$ experienced sets on the tribal and worksite poficies.

Visual displays demonstrated the expected, highly linear pattern of agreengent between experienced and inexperienced raters, and also revealed important outlier trens. Figures 2 and 3 plot the scores of all possibe pairings of experienced raters against Fexperienced raters. These displays illustrate fhat pairs of experienced and inexperienced to have wider disagreements on ribal policies (figure 2) than worksite policis (figure 3). Further, by labelling the points wth rater identification numbers, it became cfear that one experienced rater was responsible for the eight most extreme outlying points. Tा The displays add a crucial dimension to the statstical analyses, providing evidence that silong overall agreement among experienced and inexperienced raters was weakened by ogtlying points generated by a small subset of ratêrs.

\section{Discussion}

A procedure for evaluating the comprehensiveness and stringency of tobacco use policies in Indian tribe settings and worksites was developed and evaluated. The Fating system was found to be reliable for both cies, and when used by both experienced and inexperienced raters. The coefficient of concordance, a conservative noneasure of inter-judge agreement, was consisgently highmostly in the $0.80 \mathrm{~s}$ to $0.90 \mathrm{~s}$ - whether for the overall score or for specific sub-aseas or items.

The TPRF attempts to make \&oncrete and explicit conventional wisdom as fo the nature of a comprehensive and rigorousotobacco use policy. Some of this conventiona embodied in intervention matepials such as worksite smoking policy workboogs developed by volunteer health organisations and research groups. ${ }^{2027} 28$ Our thinking abougthese issues was further stimulated by experiefce conducting the Tribal Tobacco Polky Project ${ }^{17}$ (Lichtenstein $e t$ al, unpublished ̧̋bservations) wherein we developed a tobacco policy

ISee footnote on page 287 . 


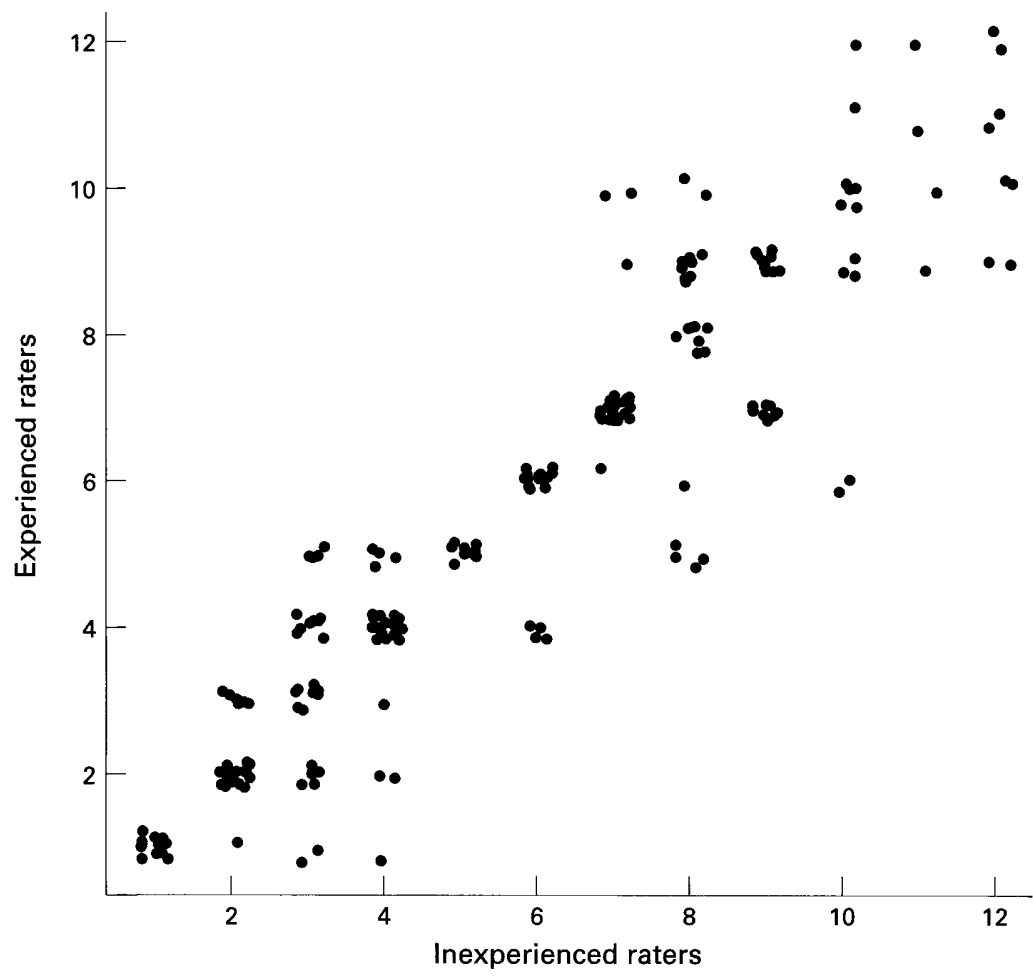

Figure 2 Total scores (15 worksites) for all pairings of experienced with inexperienced raters.

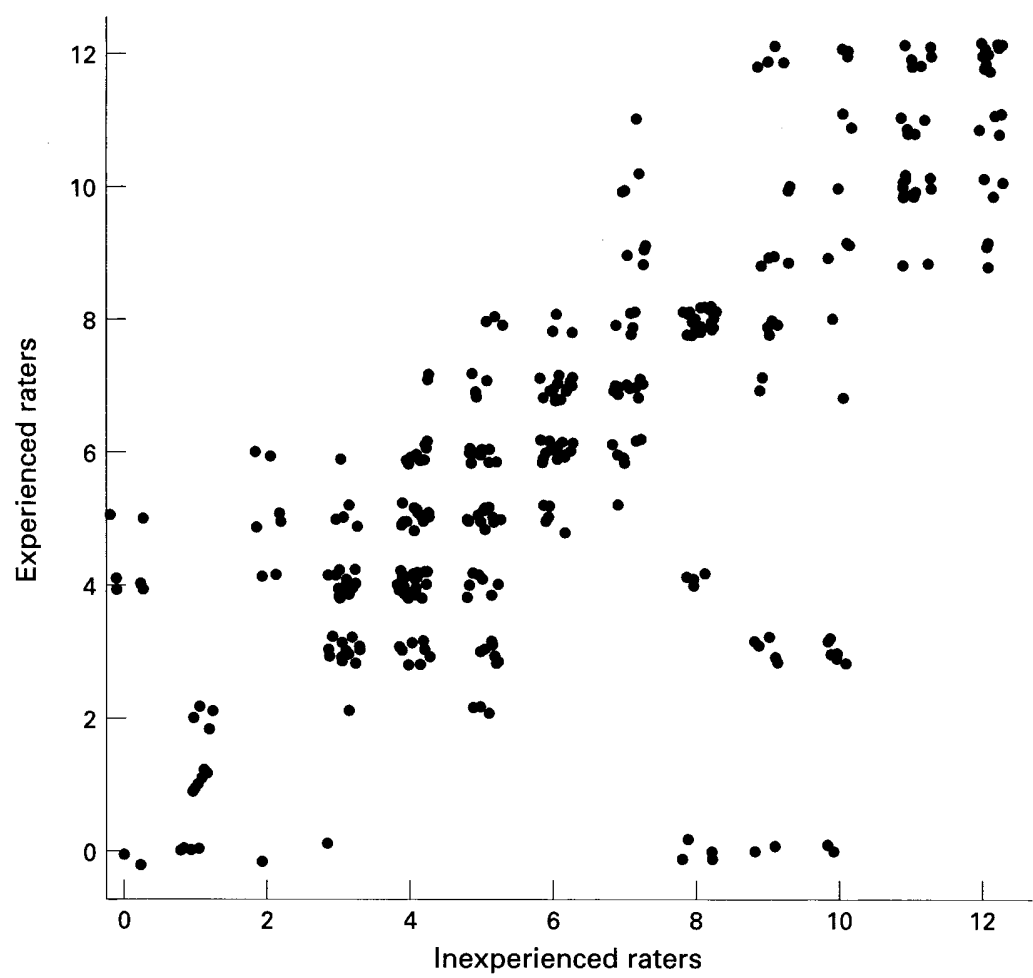

Figure 3 Total scores (24 tribes) for all pairings of experienced with inexperienced raters.

workbook for Indian settings ${ }^{19}$ and a form to provide project and tribal persons with feedback on rough drafts of tobacco use policies.

There has been a surge of interest in policy research-mostly examining the behavioural or economic consequences of policies ${ }^{6-82930}$-and a good deal of activist interest in changing policies. ${ }^{4}$ Although work has been done on the measurement of public views on policy, ${ }^{513}{ }^{131}$ we were struck by the fact that there was virtually nothing written on the measurement of the comprehensiveness or stringency of policies (other than earlier work on clean indoor gir policies at the state or community level). ${ }^{2}{ }^{2}$ The TPRF was an attempt to address this need, at least for certain kinds of settings, not $\overrightarrow{\hat{Q}^{2}}$ bly tribal settings and worksites. The instrument provides a convenient, practical way of describing a policy in a more concree and quantitative way. It also appears to be fe sible to use with a minimal amount of trainirif or expertise.

The TPRF may be appropriate to use for coding smoking policies in other settings, such as schools, churches, or community organisar tions. It is less applicable for coding more conto prehensive clean indoor air policies, such state or local regulations. The TPRF appeass to work well and its brevity is seen as strength. Future users may, however, want to consider adding another level to the "Restrictions" dimension, of a total ban on the premises.

The form can potentially be used for sever(⿻日禸 purposes. Investigators studying the behas ioural or economic consequences of policiess could use the form to provide a more detailec description of the policies under study. Those interested in policy change may find the TPRF useful as a way of describing existing policies and as a quantitative measure of change. The form may also be useful for managers or heal educators who are interested in developing ${ }_{\text {a }}$ tobacco use policy for a particular setting or for modifying an existing one. Finally, the TPR can serve as a template for evaluating a setting existing policy to help determine whether the policy is adequate or in need of revision.

There are several limitations to this stude. The tribal policies were all drawn from or geographic area of the continental Uniteo States (the Pacific northwest) and the worksige policies also constitute a convenience sampte (northeastern United States). Both sets $\Phi$ policy samples were also relatively small number. The TPRF evaluates only the writte policy and does not address enforcement 9 adherence. ${ }^{33}$ Rigotti has found that there may only be modest agreement between a writtem policy and how the policy is actual implemented. ${ }^{32}$ Nevertheless, the psychome ric data seem quite satisfactory, little trainir time was needed for inexperienced raters, and the procedure seems worthy of further use.

Future research on the TPRF by other research groups is encouraged. In particula we would like to see it used to evaluate polieg change resulting from smoking contreal interventions in worksite, tribal, schoot community, and other settings. The form $\overrightarrow{\mathrm{s}}$ publicly available and may be used withoot charge, ${ }^{\star}$ and we invite researchers communicate with us about how they use the TPRF.

*The coding and scoring systems are straightforward and can conducted by the user. If, however, centralised rating or scoring would be desired for a particular project, such services are available for a modest charge. If interested, please contact the second author (shawn@ori.org). 
This research was supported by grants NCI \#U01 CA52230-05 and NHLBI \#HL45548.

1 Brownson RC, Koffman DM, Novotny TE, Hughes RG, Eriksen MP. Environmental and policy interventions to control tobacco use and prevent cardiovascular disease. control tobacco use and prevent
Health Educ $O 1995 ; 22: 478-98$.

2 Emont SL, Choi WS, Novotny TE, Giovino GA. Clean indoor air legislation, taxation, and smoking behaviour in the United States: an ecological analysis. Tobacco Control 1992;2:13-7.

3 Glasgow RE, Sorensen G, Giffen C, et al. Promoting worksite smoking control policies and actions: The COMMIT experience. Prev Med 1996;25:186-94.

4 Pederson LL, Wanklin JM, Bull SB, Ashley MJ. A conceptual framework for the roles of legislation and education in reducing exposure to environmental tobacco smoke. Am $\mathcal{F}$ Health Prom 1991;6:105-11.

5 Velicer WF, Laforge RG, Levesque DA, Fava JL. The development and initial validation of the smoking policy inventory. Tobacco Control 1994;3:347-55.

6 Davis RM. Tobacco policy research comes of age. Tobacco Control 1995;4:6-9.

7 Patten CA, Gilpin E, Cavin SW, Pierce JP. Workplace smoking policy and changes in smoking behaviour in California: a suggested association. Tobacco Control 1995;4:36-41.

8 Burns DM, Axelrad R, Bal D, et al. Report of the tobacco policy research study group on smoke-free indoor air policies. Tobacco Control 1992;1:S19-23.

9 Pentz MA, Brannon BR, Charlin VL, Barrett EJ, MacKinnon DP, Flay BR. The power of policy: Relationship of smoking policy to adolescent smoking. Am $\mathcal{F}$ Public Health 1989; 79:857-62.

10 Biglan A, Glasgow RE. The social unit: An important facet in the design of cancer control research. Prev $\mathrm{Med}$ 1991;20:292-305.

11 Eriksen MP, LeMaistre CA, Newell GR. Health hazards of passive smoking. Annu Rev Public Health 1988;9:47-70.

12 Rigotti NA, Pashos CL. No-smoking laws in the United States: An analysis of state and city actions to limit smoking in public places and workplaces. $\mathscr{f} A M A 1991$ 266:3162-7.

13 Forster JL, McBride C, Jeffery R, Schmid TL, Pirie LP. Support for restrictive tobacco policies among residents of selected Minnesota communities. Am F Health Prom 1991; 6: $99-104$

14 Glasgow RE, Terborg JR, Hollis JF, et al. Modifying dietary and tobacco use patterns in the worksite: The Take Heart Project. Health Educ Q 1994;21:69-82.

15 Glasgow RE, Terborg JR, Hollis JF, Severson HH, Boles SM. Take Heart: Results from the initial phase of a worksite wellness program. Am F Public Health 1995;85:20916.

16 Glasgow RE, Terborg JR, Strycker LA, Boles SM, Severson HH, Hollis JF. Take Heart II: A replication of a worksite health promotion trial. $₹$ Behav Med. In press.

17 Lichtenstein E, Glasgow R, Lopez K, Hall R, Gilbert McRae S, Meyers GB. Promoting tobacco control policies in Northwest Indian tribes. Am $\mathcal{f}$ Public Health 1995; 85:991-4

18 Glasgow RE, Lichtenstein $E$, Wilder $D$, Hall $R$, Gilbert McRae S, Liberty B. The Tribal Tobaco Policy Project: Working with Northwest Indian tFibes on smoking Working with Northwest Indian t9ib

19 Northwest Portland Area Indian Heaßh Board, Oregon Research Institute, and Oregon State University. Tribal tobacco policy project workbook. Trib@ Tobacco Policy Project. Portland, Oregan: NPAIHB, 1.995.

20 Oregon Research Institute. Steering cinmittee guidebook. Take Heart Worksite Health Imprawement Program Eugene, Oregon: Oregon Research Insరtute, 1991.

21 Strycker L, Foster L, Pettigrew L, Ferry J, Jordan S Glasgow R. Steering committee enhandements on health promotion program delivery. $A m \mathcal{F} \mathrm{He} \mathscr{C}$ Prom. In press.

22 Terborg JR, Glasgow RE. Worksite interventions: A brief review of health promotion programs afwork. In: Baum A, McManus C, Newman S, Weinmâ J, West R, eds Cambridge handbook of psychology, health and medicine. Lambridge handbook of psychology, health

23 Gibbons JD. Nonparametric measures of association. Newbury Park, California: Sage, 1993.

24 Conger AJ. Integration and generaliz $400 \mathrm{n}$ of kappas for multiple raters. Psychol Bull 1980;88:3 $28-8$.

25 Siegel S. Nonparametric statistics for thebehavioral sciences. New York: McGraw-Hill, 1956

26 Cleveland WS. Visualizing data. Sunimit, New Jersey: Hobart, 1993. No

27 Institute for the Study of Smoking B Begavior and Policy. COMMIT guide to nonsmoking policies for small businesses. Bethesda, Maryland: Community Intervention Trial for Smoking Cessation, National Cancer Institute, 1989.

28 National Lung Association. On the air-ge guide to creating a smoke-free workplace. New York American Lung Association. 1988.

29 Glanz K, Lankenau B, Foerster S, Te Schmid T. Environmental and polach approaches to cardiovascular disease prevention throagh nutrition: Opportunities for state and local action. Health Educ $Q 1995$; portunities for state and local action. Schwartz R, Goodman R, Steckler A. Pog gy advocacy interventions for health promotion and .education (Specia issue). Health Educ $Q$ 1995;22:421-6.

31 Mattson ME, Cummings KM, Lynn WQ, et al. Evaluation plan for the Community Interventions Irial for Smoking Cessation (COMMIT). Int $Q$ Commur Health Educ 1990 11:271-90.

32 Rigotti NA. Trends in the adoption of in public places and worksites. State $f \mathrm{Med}$ 1989;89:19-26.

33 Hall RL, Viles CA, Lichtenstein E, Glas $\overrightarrow{\text { 似 }}$ RE, Lopez KI Rapid assessment procedures to desçibe tobacco practices at sites managed by Indian tribes. Tobacco Control 1995;4:156-61.

34 Sorensen G, Thompson B, Glanz K, 飶al. Working Well: Results from a worksite-based cancer psevention trial. $A m$

\section{One hundred years ago}

INFANT SMOKERS f Public Health 1996;86:939-47.

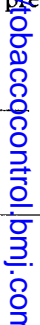

until they are about 4 years of age; he declares that more than once he has seen a child take its whack from his mother's bosom and subsequently take his whiff at a cheroot or from any other sing material that was handy."

(BMF 1896;April 11:956.) 